\title{
Does zafirlukast reduce future risk of asthma exacerbations in adults? Systematic review and meta-analysis
}

\author{
Chao Feng Chen, Yan Lv, Hong Ping Zhang and Gang Wang*
}

\begin{abstract}
Background and objective: The purpose of asthma management is to achieve a total asthma control that involves current control and future risk. It has proven efficacy in reducing asthma exacerbations, but the effect size of zafirlukast for asthma exacerbations of various severity is not systematically explored.

Methods: Randomized controlled trials were searched in PubMed Central, Web of Science, and Embase, where zafirlukast prevented asthma exacerbations in adults. The primary outcome was asthma exacerbations, the secondary outcomes were asthma exacerbations requiring systemic corticosteroids and emergency visits, respectively. Odds ratio (OR) with $95 \%$ confidence intervals (Cl) were pooled.

Results: Twelve trials were identified. As first-line therapy, compared to those having placebo, the patients with chronic asthma receiving zafirlukast experienced statistically lower asthma exacerbations $(\mathrm{OR}=0.68,95 \% \mathrm{Cl}=[0.45$, 1.00]), but it was not found that zafirlukast was superior to placebo in asthma exacerbations requiring systemic corticosteroids $(\mathrm{OR}=0.76,95 \% \mathrm{Cl}=[0.45,1.29])$. Furthermore, zafirlukast was inferior to $\mathrm{ICs}$ in asthma exacerbations $(\mathrm{OR}=2.11,95 \% \mathrm{Cl}=[1.35,3.30])$ and requiring systemic corticosteroids $(\mathrm{OR}=3.71,95 \% \mathrm{Cl}=[1.82,7.59])$. As add-on therapy, zafirlukast was not superior to placebo in asthma exacerbations $(\mathrm{OR}=0.99,95 \% \mathrm{Cl}=[0.54,1.81]$ and requiring emergency visits $(\mathrm{OR}=0.72,95 \% \mathrm{Cl}=[0.18,2.99])$. Intriguingly, there was not a significant difference in asthma exacerbations between zafirlukast and ICs (OR $=1.12,95 \% \mathrm{Cl}=[0.53,2.34])$.

Conclusions: Our study suggests that zafirlukast, as the first-line therapy, significantly reduces mild to moderate but not severe asthma exacerbations. In the add-on regimen, zafirlukast could not reduce asthma exacerbations, which would perhaps result from small sample size and needs to be further studied.
\end{abstract}

Keywords: Asthma exacerbations, First-line and add-on therapy, Meta-analysis, Systematic review, Zafirlukast

\section{Introduction}

Asthma is a chronic inflammatory disorder of airways closely associated with airway hyperresponsiveness. It is estimated that around 300 million people suffer from asthma and the burden of this disease to governments, health care systems, families, and patients is increasing worldwide [1,2]. Despite advances in knowledge of the pathophysiology of asthma and availability of effective therapy, currently asthma cannot be cured yet.

\footnotetext{
* Correspondence: wcums-respiration@hotmail.com

Pneumology Group, Department of Integrated Traditional Chinese and Western Medicine, West China Hospital, Sichuan University, Chengdu 610041, People's Republic of China
}

The goal of asthma treatment is to achieve and maintain asthma optimal control, which includes current control and long-term components referred to as "risk" or "future risk" since 2009 [3]. Asthma control is evaluated by a global assessment of asthma symptoms, reliever medicine use, lung function, and the frequency/ severity of exacerbations. It is disappointing that only $2 \%$ of asthma patients are considered controlled across eight Asia-Pacific countries and Hong Kong in real world settings when control is assessed using the Global Initiative for Asthma (GINA) classification [4]. Asthma exacerbations, as the most important future risk, are recognized as a common clinical manifestation in patients with severe asthma, and are known to increase the risk of asthma 
mortality [5]. Hence, in recent years to prevent asthma exacerbations has been identified as an important component of establishing ideal asthma control in all asthma treatment guidelines. Inhaled corticosteroids (ICs) and combination of ICs/long-acting $\beta_{2}$-agonists (LABA) are the mainstay of therapy for reducing asthma exacerbations including the severe ones, but some patients require additional treatment or prefer not to use ICs. In such patients, leukotriene receptor antagonist (LTRA), is a promising alternative to ICs therapy.

Although LTRA has been proven to be effective in improving asthma control in clinical practice, few studies systematically focused on effects of LTRA on future asthma outcomes, such as exacerbations and their various types. Furthermore, the relative effect size of LTRAs for prevention of future risk of asthma exacerbations remains unclear. Also because there is a great heterogeneity in pooled data of different types of LTRA, such as montelukast, zafirlukast, panlukastandzileuton [6]. This systematic review and meta-analysis is aimed to explore effects of zafirlukast, as first-line and add-on therapy, on prevention of asthma exacerbations in adults.

\section{Methods}

\section{Search strategy and selection criteria}

We searched electronic databases including PubMed (1991 to June 2013), Embase (1992 to June 2013) and Web of Science (1992 to June 2013) for randomized controlled trials (RCTs) using a comprehensive search strategy including the following keywords: "zafirlukast AND (asthma or wheezing), Limits Activated: Randomized Controlled Trial (RCT)". We reviewed reference lists of all included studies, systematic reviews and narrative reviews to identify potentially relevant citations. There was no limitation on language or year of publication.

Trials were included if they met the following criteria: they were randomized controlled trials comparing zafirlukast versus placebo or other active drugs and reporting at least one asthma exacerbation. The trials were excluded if the patients were hospitalized for acute asthma because the primary outcome of this study for zafirlukast in treating asthma included hospitalization for asthma exacerbation. After exclusion of duplicates, two reviewers (C.F.C. and Y.L.) reviewed the full text of all citations with titles and abstracts that seemed to fit the criteria of inclusion. Irrelevant citations or not randomized controlled trials were not reviewed in full text. The number of citations rejected and the reasons for rejection were tracked.

\section{Data extraction and quality assessment}

We reviewed each eligible citation, and obtained the full text of all definite of possible randomized controlled trials. From each article we extracted details regarding authors, year of publication, sex, sample size, sample size calculation, standard treatments, interventions as the first-line or addon therapies, outcomes, adverse events, and intention to treat analysis and so on.

The methodological quality of included trials was assessed independently by two reviewers (CFC and YL). If information was not reported adequately, authors or sponsors of each included trial were contacted to acquire the accuracy of the methodology and primary data. The quality of the methods of each trial was assessed with the Cochrane Collaboration's tool for assessing risk of bias [7]. Our judgments of high, low, and unclear risk of bias were corroborated by citations from trial reports, correspondence, or summarized information from the relevant sections of the individual study reports. Any disagreement between reviewers was resolved by consensus or by the third reviewer (G.W.).

\section{Primary and secondary outcomes}

In the meta-analysis assessing the prevention of zafirlukast from asthma exacerbations, the number of asthma exacerbations was a priori specified primary outcome so as the number of detailed different exacerbations such as requiring systemic corticosteroids, whereas emergency visits and hospitalizations were identified as secondary outcomes.

\section{Statistical analysis, and assessment and evaluation of the evidence quality}

The included trials were divided into two types of analyses stratified by zafirlukast as the first-line or the addon therapies. The mean daily dose of ICs was converted in "microgram $(\mu \mathrm{g})$ of beclomethasone equivalent". Asthma exacerbations as dichotomous variables were reported as odds ratio (OR).

Heterogeneity was assessed by means of the Cochran $\mathrm{Q}$ method and by the test of inconsistency $\left(\mathrm{I}^{2}\right)$. A random effects model was used if the Q statistic $(\mathrm{p}<0.1)$ or $\mathrm{I}^{2}(>50 \%)$ was significant, or we used a fixed effects model. We carried out subgroup analysis to assess the source of heterogeneity and we assessed the presence of publication bias visually with a funnel plot. Differences in bias risk and number needed to treat (NNT) were calculated to assess clinical significance. All estimates were reported with 95\% confidence intervals (CI) and all $\mathrm{p}$ were 2-tailed. The meta-analysis was performed with Stata 11.0 (Stata Corp LP, College Station, Texas), and the risk bias of the methodological quality was assessed using RevMan 5.1 (Cochrane Review Manager, The Cochrane Collaboration, Oxford, UK).

The quality of the evidence related to the estimation of benefits and disadvantages in asthma exacerbation in adult population requiring oral/parenteral corticosteroid or emergency visits followed the suggestions of the GRADE Working Group (http://www.gradeworkinggroup. 
org/index.htm) by adopting the use of GradePro software 3.6 (http://ims.cochrane.org/revman/gradepro).

\section{Results}

\section{Trials included, study characteristics and quality of} reporting

The search strategy initially yielded 313 citations. Figure 1 shows details of study identification, inclusion and exclusion. Twelve unique trials with 4,398 participants which met the inclusion criteria came into statistical analysis [8-19]. All the trials recruited adults and adolescents. The characteristics of the included studies are listed in Table 1. The intervention period ranged from 4 to 48 weeks (median: 26 weeks). There were two types of interventions for zafirlukast, and they were first-line $(\mathrm{n}=10)$ or add-on $(\mathrm{n}=4)$ treatments. The dosage of zafirlukast was administrated $20 \mathrm{mg}$ twice a day, except for two trials $[14,19]$, where patients were treated with zafirlukast $80 \mathrm{mg}$ twice daily, or were given $5 \mathrm{mg}, 10 \mathrm{mg}$ and $20 \mathrm{mg}$ twice daily, respectively. The number of patients included in these studies varied between 38 and 762. In included studies with chronic persistent asthma, $\mathrm{FEV}_{1} \%$ of predicted value at baseline was more than $45 \%$. In general, rescue $\beta_{2}$-agonists were permitted.

All the included trials were randomized and controlled. Table 2 shows an overview of the risk bias of each trial. There was no conflict of interest among eligible studies. Double blinding was used in all trials. On the whole, most of the included studies were of high methodological quality.

\section{Outcomes for meta-analysis \\ First-line therapy}

The primary and secondary outcomes are shown in Figure 2. Compared to those having placebo, the patients with chronic asthma receiving zafirlukast experienced statistically lower asthma exacerbations $(\mathrm{OR}=0.68,95 \% \mathrm{CI}=$ $[0.45,1.00])$. However, zafirlukast as the first-line therapy in chronic asthma was not superior to placebo in requiring systematic corticosteroids for asthma exacerbation $(\mathrm{OR}=0.76,95 \% \mathrm{CI}=[0.45,1.29])$. Furthermore, zafirlukast was inferior to ICs in patients experiencing asthma exacerbations $(\mathrm{OR}=2.11,95 \% \mathrm{CI}=[1.35,3.30])$ and asthma exacerbations requiring systematic corticosteroids $(\mathrm{OR}=$

Potentially relevant abstracts identified and screened: search strategy: zafirlukast and (asthma or wheezing)

limits: randomized controlled trial

Citation screened for titles and abstracts $(\mathrm{n}=313)$

Duplicate publication $(\mathrm{n}=96)$

Unique abstracts identified(n=217)

Unrelated trials excluded $(\mathrm{n}=187$

Detailed information evaluated $(\mathrm{n}=30)$

Excluded with reasons $(\mathrm{n}=6)$

- Letters $(n=1)$

- Only abstract publication $(n=2)$

- Incomplete data $(n=2)$

- Open label observation( $\mathrm{n}=1)$

- The intervention shorter than 1 week $(\mathrm{n}=1)$

- Without asthma exacerbation in outcomes $(\mathrm{n}=12)$

Eligible trials $(\mathrm{n}=12)$

Figure 1 Flow diagram of trial selection and details of study identification, inclusion and exclusion. 
Table 1 Characteristic of the included trials

\begin{tabular}{|c|c|c|c|c|c|c|c|c|c|c|c|c|}
\hline \multirow[t]{2}{*}{ Study ID } & \multirow[t]{2}{*}{$\begin{array}{l}\text { Age mean } \pm S D \\
\text { [Range], y }\end{array}$} & \multirow[t]{2}{*}{$\begin{array}{l}\text { Gender } \\
\text { (F/M) }\end{array}$} & \multirow[t]{2}{*}{ Intervention } & \multirow[t]{2}{*}{$\begin{array}{l}\text { Standard } \\
\text { treatments }\end{array}$} & \multirow[t]{2}{*}{$\begin{array}{l}\text { Compliance } \\
(\%)\end{array}$} & \multirow[t]{2}{*}{$\mathrm{FEV}_{1} \%$} & \multirow[t]{2}{*}{$\begin{array}{l}\text { Run in } \\
\text { period }\end{array}$} & \multirow[t]{2}{*}{$\begin{array}{l}\text { Treatment } \\
\text { duration }\end{array}$} & \multirow[t]{2}{*}{$\begin{array}{l}\text { Type of } \\
\text { intervention }\end{array}$} & \multicolumn{3}{|c|}{$\begin{array}{l}\text { Reported } \\
\text { outcomes }\end{array}$} \\
\hline & & & & & & & & & & $\overline{\mathrm{AE}}$ & AES & AEE \\
\hline \multirow{3}{*}{$\begin{array}{l}\text { Boushey HA } \\
2005[8]\end{array}$} & T: $33.6 \pm 11.1$ & T: 47/29 & T: Z 20 mg + IP bid & \multirow{3}{*}{$\begin{array}{l}\text { IB } 800 \text { ug bid } \times 10 D \\
\text { or prednisone } \times 5 D \\
\text { if asthma worsened }\end{array}$} & \multirow[t]{3}{*}{$>90$} & \multirow[t]{3}{*}{$\geq 70$} & \multirow[t]{3}{*}{4 weeks } & \multirow[t]{3}{*}{48 weeks } & \multirow[t]{3}{*}{ First-line/add-on } & \multirow[t]{3}{*}{+} & \multirow[t]{3}{*}{-} & \multirow[t]{3}{*}{+} \\
\hline & $C 1: 33.2 \pm 9.5$ & C1: $48 / 25$ & C1: IB 200 ug + OP bid & & & & & & & & & \\
\hline & $C 2: 32.0 \pm 10.5$ & $C 2: 43 / 33$ & $C 2: I P+O P$ bid & & & & & & & & & \\
\hline \multirow{2}{*}{$\begin{array}{l}\text { Huang CJ } \\
2003[9]\end{array}$} & $\mathrm{T}: 58.6 \pm 3.0$ & $\mathrm{~T}: 8 / 9$ & T: Z 20 mg bid & \multirow{2}{*}{$\begin{array}{l}\text { IB ( } \geq 400 \mu \mathrm{g} / \text { day or } \\
\text { equivalent })+ \text { SABA }\end{array}$} & \multirow[t]{2}{*}{$N R$} & \multirow[t]{2}{*}{ Moderate } & \multirow[t]{2}{*}{2 weeks } & \multirow[t]{2}{*}{4 weeks } & \multirow[t]{2}{*}{ Add-on } & \multirow[t]{2}{*}{+} & - & + \\
\hline & C: $56.9 \pm 2.8$ & $C: 7 / 7$ & C: Placebo 20 mg bid & & & & & & & & & \\
\hline Brabson JH & $\mathrm{T}: 35 \pm 16$ & T: $141 / 75$ & T: Z 20 mg bid & Albuterol as needed & $\geq 88$ & $60-85$ & 8 days & 6 weeks & First-line & + & + & + \\
\hline & $C: 36 \pm 14$ & C: $134 / 90$ & C: IFP 88 ug bid & & & & & & & & & \\
\hline Nathan RA & $\mathrm{T}: 32$ & T: 65/85 & T: Z 20 mg bid & Albuterol as needed & $N R$ & $50-80$ & 7-14 days & 4 weeks & First-line & + & - & - \\
\hline 200 & C: 31 & C: $79 / 65$ & C: Fluticasone 88 ug bid & & & & & & & & & \\
\hline Busse W & $\mathrm{T}: 12-75$ & $\mathrm{~T}: \mathrm{NR}$ & $\mathrm{T}: \mathrm{Z} 20 \mathrm{mg}+\mathrm{IP}$ bid & Albuterol as needed, & $N R$ & $50-80$ & 8-14 days & 12 weeks & First-line/add-on & + & + & - \\
\hline & C: $12-75$ & $C: N R$ & C1: IFP 88 ug + OP bid & $\begin{array}{l}\text { or oral or parental } \\
\text { corticosteriods for AE }\end{array}$ & & & & & & & & \\
\hline & & & $C 2: I P+O P$ bid & & & & & & & & & \\
\hline Kim KT & T: 32.9 & T: 127/89 & T: Z 20 mg + IP bid & Albuterol as needed & 88 & $60-85$ & 1 week & 6 weeks & First-line & + & + & + \\
\hline & C: 35.5 & C: $135 / 86$ & C: IFP 88 ug bid & & & & & & & & & \\
\hline Virchow JCJr & $\mathrm{T}: 47.4 \pm 12.6$ & T: 85/95 & T: Z 80 mg bid & Beclomethasone $\geq$ & T: 95 & $50-75$ & 2 weeks & 6 weeks & Add-on & + & - & - \\
\hline & C: $49.2 \pm 12.9$ & C: $98 / 90$ & C: Placebo $80 \mathrm{mg}$ bid & $\begin{array}{l}\text { I } 200 \text { ug/day or } \\
\text { equivalent) + SABA }\end{array}$ & C: 94 & & & & & & & \\
\hline Bleecker ER & $\mathrm{T}: 31$ & T: 113/107 & $\mathrm{T}:$ Z $20 \mathrm{mg}$ bid & Albuterol as needed & 92 & $50-80$ & 8-14 days & 12 weeks & First-line & + & - & - \\
\hline & C: 31 & C: $112 / 119$ & C: IFP 88 ug bid & & & & & & & & & \\
\hline Busse W & T: 36.9 & T: 85/60 & $\mathrm{T}:$ Z $20 \mathrm{mg}$ bid & Albuterol as needed & $N R$ & $50-80$ & 7-14 days & 4 week & First-line & + & - & - \\
\hline & C: 38.6 & C: $77 / 67$ & C: SX 42 ug bid & & & & & & & & & \\
\hline Nathan RA & T: 33.2 & T: $127 / 104$ & $\mathrm{~T}:$ Z $20 \mathrm{mg}$ bid & SABA as needed & $N R$ & $45-80$ & 2-3 weeks & 13 weeks & First-line & + & + & - \\
\hline & C: 32.1 & C: $132 / 91$ & C: Placebo 20 mg bid & & & & & & & & & \\
\hline Fish JE & $\mathrm{T}:>12$ & T: 220/294 & T: Z 20 mg bid & Albuterol as needed & $N R$ & $>55$ & 7-14 days & 13 weeks & First-line & + & - & - \\
\hline & $C:>12$ & C: $102 / 146$ & C: Placebo 20 mg bid & & & & & & & & & \\
\hline $\begin{array}{l}\text { Spector SL } \\
1994 \text { [19] }\end{array}$ & $\begin{array}{l}\text { T: Z1: 37, Z2: 35, } \\
\text { Z3: } 36, C: 36\end{array}$ & $\begin{array}{l}\text { T: Z1: 18/52, Z2: 23/45, } \\
\text { Z3: 18/50, C: 20/50 }\end{array}$ & $\begin{array}{l}\text { T: Z1: } 20 \mathrm{mg} \text { bid, } \\
\text { Z2: } 10 \mathrm{mg} \text { bid, Z3: } 5 \mathrm{mg} \\
\text { bid, C: Placebo bid }\end{array}$ & Albuterol as needed & $N R$ & $40-75$ & 2 weeks & 6 weeks & First-line & + & - & - \\
\hline
\end{tabular}

$\mathrm{AE}$, asthma exacerbations; $\mathrm{AEE}$, asthma exacerbation require emergency visits; $\mathrm{AES}$, asthma exacerbation require systematic corticosteroid; bid, twice daily; $C$, control group; $\mathrm{D}$, days; $\mathrm{F}$, female; $\mathrm{IB}$, inhalation budesonide; IFP, inhalied fluticasone propionate; IP, inhalation of placebo; M, male; NR, not reported; OP, oral placebo; SABA, short $\beta_{2}$ agonist; SD, standard deviation; SX, Salmeterolxinafoate; T, treatment group; $y$, year; $Z$, zafirlukast; +, positive report; - , negative report. 
Table 2 Methodological quality of included studies

\begin{tabular}{|c|c|c|c|c|c|c|c|c|c|c|c|}
\hline Study & $\begin{array}{l}\text { Randomly } \\
\text { assigned }\end{array}$ & $\begin{array}{c}\text { Allocation } \\
\text { concealment }\end{array}$ & Multi- center & Blinding & $\begin{array}{l}\text { Complete outcome } \\
\text { data adequately } \\
\text { addressed }\end{array}$ & $\begin{array}{l}\text { Free of selective } \\
\text { outcomes reporting }\end{array}$ & $\begin{array}{l}\text { Other } \\
\text { bias }\end{array}$ & $\begin{array}{l}\text { Intention } \\
\text { to treat }\end{array}$ & $\begin{array}{l}\text { Sample size } \\
\text { calculation }\end{array}$ & Power & $\begin{array}{c}\text { Conflict of } \\
\text { interest }\end{array}$ \\
\hline Boushey 2005 [8] & Yes & Yes & Yes & Double-blind & Yes & Unclear & Unclear & No & Yes & 0.90 & No \\
\hline Huang 2003 [9] & Yes & Yes & No & Double-blind & Yes & Unclear & Unclear & No & No & NA & No \\
\hline Brabson 2002 [10] & Yes & Yes & Yes & Double-blind & Yes & Unclear & Unclear & Yes & Yes & 0.80 & No \\
\hline Nathan 2001 [11] & Yes & Yes & Yes & Double-blind & Yes & Unclear & Unclear & No & Yes & 0.80 & No \\
\hline Busse 2001 [12] & Yes & Yes & No & Double-blind & Yes & Unclear & Unclear & No & Yes & 0.80 & No \\
\hline Kim 2000 [13] & Yes & Yes & No & Double-blind & Yes & Unclear & No & Yes & Yes & 0.80 & No \\
\hline Virchow 2000 [14] & Yes & Yes & Yes & Double-blind & Yes & Unclear & Unclear & No & No & NA & No \\
\hline Bleecker 2000 [15] & Yes & Yes & Yes & Double-blind & Yes & Unclear & No & Yes & Yes & 0.80 & No \\
\hline Busse 1999 [16] & Yes & Yes & Yes & Double-blind & Yes & Unclear & Unclear & Yes & Yes & 0.80 & No \\
\hline Nathan 1998 [17] & Yes & Yes & Yes & Double-blind & Yes & Unclear & Unclear & No & Yes & 0.90 & No \\
\hline Fish 1997 [18] & Yes & Yes & Yes & Double-blind & Yes & Unclear & Unclear & No & Yes & 0.90 & No \\
\hline Spector 1994 [19] & Yes & Yes & Yes & Double-blind & Yes & Unclear & No & No & Yes & 0.90 & No \\
\hline
\end{tabular}




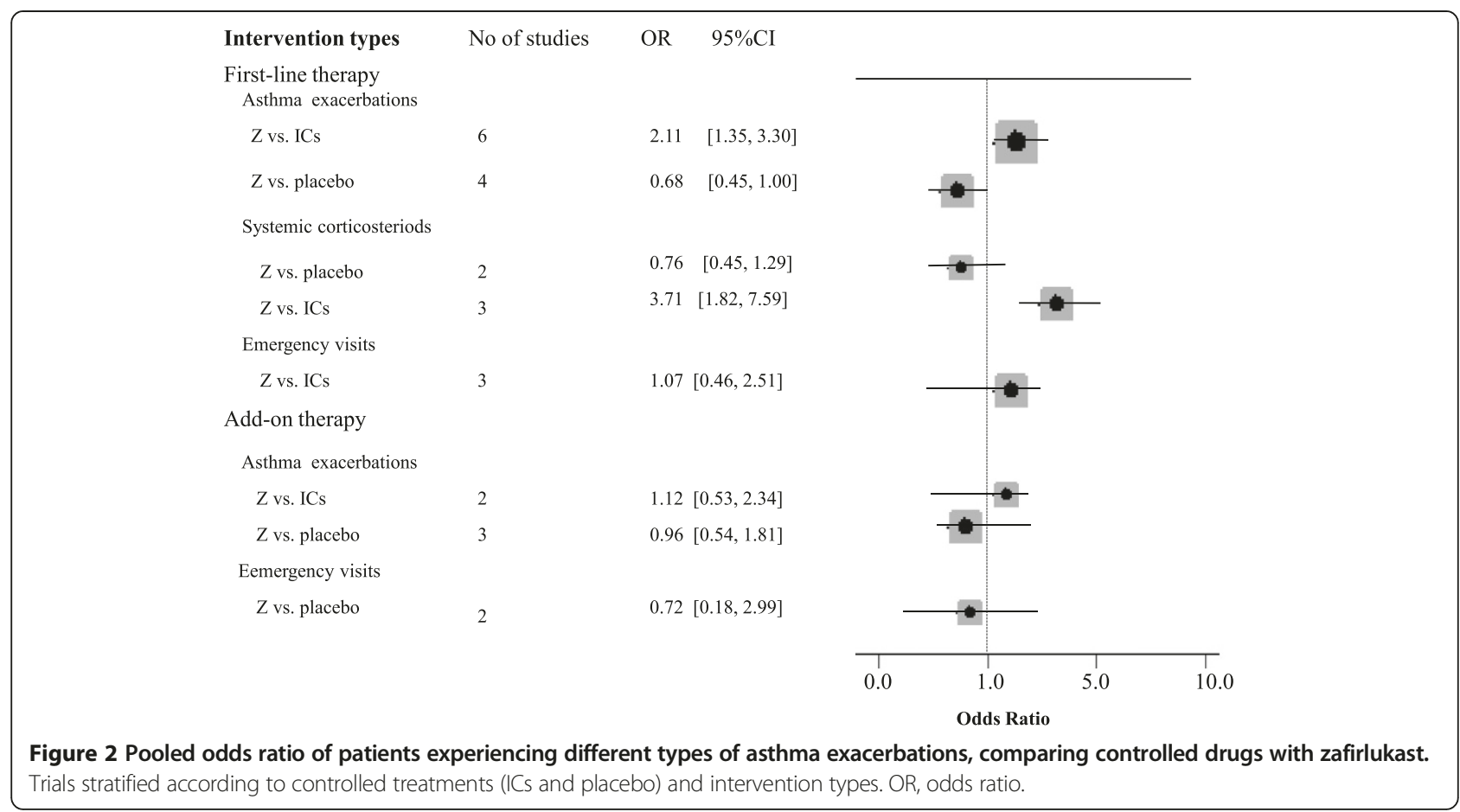

$3.71,95 \% \mathrm{CI}=[1.82,7.59])$ but not in those requiring emergency visits $(\mathrm{OR}=1.07,95 \% \mathrm{CI}=[0.46,2.51])$.

In placebo-controlled studies, only two trials which had met the inclusion criteria about patients requiring systematic corticosteroids for asthma exacerbations came into meta-analysis, so we could not perform subgroup and sensitivity analysis. Our subgroup and sensitivity analysis in ICs-controlled studies indicated that long-term ICs with more than 12 weeks did not get much more benefit in emergency visits in comparison to that with less than 12 weeks $(\mathrm{OR}=2.56,95 \% \mathrm{CI}=[0.80,8.20]$ vs. $\mathrm{OR}=$ $1.07,95 \% \mathrm{CI}=[0.46,2.51])$.

\section{Add-on therapy}

When zafirlukast was taken as an add-on therapy, we unexpectedly found it was not superior to placebo in asthma exacerbations $(\mathrm{OR}=0.99,95 \% \mathrm{CI}=[0.54,1.81]$ and emergency visits $(\mathrm{OR}=0.72,95 \% \mathrm{CI}=[0.18,2.99])$. Intriguingly, there was not a significant difference in asthma exacerbations between zafirlukast and ICs $(\mathrm{OR}=1.12$, 95\% $\mathrm{CI}=[0.53,2.34]$.

\section{Assessment and recommendation of zafirlukast for prevention of asthma exacerbations}

The details are shown in Table 3. We assessed the asthma exacerbations and the participants who required emergency visits or needed systemic corticosteroids because of asthma exacerbations. According to the methodology of each trial, the quality of evidence of zafirlukast as first-line treatment compared with placebo, first-line/ add-on treatment compared with ICs was of low or moderate quality. The trials failed to undertake intentionto-treat analysis and publication of bias in the funnel plot among the trials contributed to decrease the quality of evidence.

\section{Discussion}

According to GINA report, the goal of asthma management is to achieve and maintain optimal asthma control [2]. Recently, the concept of asthma control has been extended to include an assessment of future risk in addition to the previous focus on the current impairment from asthma [20,21]. Despite advances in knowledge of the pathophysiology of asthma and via availability of effective therapy, asthma cannot currently be cured yet. As the most important factors in future risk of asthma, asthma exacerbations are common in asthmatic patients' life, and constitute a major burden on health care resources. In patients with chronic mild to moderate asthma, zafirlukast significantly reduced asthma exacerbations in the first-line regimen when compared to placebo, but we did not find that zafirlukast was superior to placebo in asthma exacerbations in add-on regimen. Furthermore, zafirlukast was inferior to ICs in reducing asthma exacerbations and asthma exacerbations requiring systemic corticosteroids. It suggested that there was no absolute advantage from zafirlukast in relieving severe asthma attack such as asthma exacerbations requiring systemic corticosteroids or emergency visits. 
Table 3 Assessment of benefits and disadvantages in asthma exacerbation

\begin{tabular}{|c|c|c|c|c|c|c|c|}
\hline \multirow[t]{2}{*}{ Clinical outcomes } & \multirow[t]{2}{*}{ Comparisons } & \multirow{2}{*}{$\begin{array}{l}\text { Therapy } \\
\text { type }\end{array}$} & \multicolumn{2}{|c|}{ Illustrative comparative risk } & \multirow{2}{*}{$\begin{array}{l}\text { Relative effect } \\
(95 \% \mathrm{Cl})\end{array}$} & \multirow{2}{*}{$\begin{array}{l}\text { No. of } \\
\text { participants } \\
\text { (studies) }\end{array}$} & \multirow{2}{*}{$\begin{array}{l}\text { Quality of } \\
\text { evidence (GRADE) }\end{array}$} \\
\hline & & & $\begin{array}{l}\text { With } \\
\text { comparator }\end{array}$ & $\begin{array}{l}\text { With } \\
\text { intervention }\end{array}$ & & & \\
\hline \multirow[t]{4}{*}{ Asthma exacerbation } & Zafirlukast vs. placebo & First-line & $92 / 1000$ & $\begin{array}{l}62 / 1000 \\
(44 \text { to } 92)\end{array}$ & $\mathrm{OR}=0.68[0.45,1.00]$ & $1,255(n=4)$ & $\oplus \oplus \ominus \ominus$ Low $^{1}$ \\
\hline & Zafirlukast vs. ICs & First-line & $31 / 1000$ & $\begin{array}{l}64 / 1000 \\
\text { (42 to } 96)\end{array}$ & $\mathrm{OR}=2.11[1.35,3.30]$ & $1,963(n=6)$ & $\oplus \oplus \oplus \ominus$ Moderate $^{2}$ \\
\hline & Zafirlukast vs. ICs & Add-on & $83 / 1000$ & $\begin{array}{l}92 / 1000 \\
(46 \text { to } 175)\end{array}$ & $\mathrm{OR}=1.12[0.53,2.34]$ & $353(n=2)$ & $\oplus \oplus \ominus \ominus \mathrm{Low}^{3}$ \\
\hline & Zafirlukast vs. placebo & Add-on & $121 / 1000$ & $\begin{array}{l}120 / 1000 \\
\text { (69 to } 200)\end{array}$ & $\mathrm{OR}=0.96[0.54,1.81]$ & $383(n=3)$ & $\oplus \oplus \ominus \ominus \mathrm{Low}^{4}$ \\
\hline \multirow{2}{*}{$\begin{array}{l}\text { Asthma exacerbation } \\
\text { requiring systemic } \\
\text { corticosteriod }\end{array}$} & Zafirlukast vs. placebo & First-line & 108/1000 & $\begin{array}{l}86 / 1000 \\
(40 \text { to } 186)\end{array}$ & $\mathrm{OR}=0.76[0.45,1.29]$ & $544(n=2)$ & $\oplus \oplus \ominus \ominus$ Low $^{5}$ \\
\hline & Zafirlukast vs. ICs & First-line & $18 / 1000$ & $\begin{array}{l}64 / 1000 \\
\text { (32 to } 123)\end{array}$ & $\mathrm{OR}=3.71[1.82,7.59]$ & $1,089(n=3)$ & $\oplus \oplus \oplus \ominus$ Moderate $^{6}$ \\
\hline \multirow{2}{*}{$\begin{array}{l}\text { Asthma } \\
\text { exacerbation requiring } \\
\text { emergency treatment }\end{array}$} & Zafirlukast vs. ICs & First-line & $22 / 1000$ & $\begin{array}{l}23 / 1000 \\
\text { (10 to } 53)\end{array}$ & $\mathrm{OR}=1.07[0.46,2.51]$ & $994(n=3)$ & $\oplus \oplus \ominus \ominus$ Low $^{7}$ \\
\hline & Zafirlukast vs. placebo & Add-on & $60 / 1000$ & $\begin{array}{l}44 / 1000 \\
\text { (11 to } 159)\end{array}$ & $\mathrm{OR}=0.72[0.18,2.99]$ & $163(n=3)$ & $\oplus \oplus \ominus \ominus$ Low $^{8}$ \\
\hline
\end{tabular}

$\mathrm{Cl}_{1}=$ confidence intervals; $\mathrm{ICs},=$ inhaled corticosteroids; $\mathrm{OR}$, odds ratio.

1 (-1 limitations) ( -1 publication bias). Four trials (Boushey HA 2005, Busse W 2001, Fish JE 1997, Nathan RA 1998) have high quality, but all of them fail to adhere to an intention-to-treat analysis, so suggesting high likelihood of bias ( -1 of quality). Four trials were included, from the funnel plot we strongly suspected there was publication bias.

2 (-1 limitations). Busse W 2001 and Nathan RA 1998 fail to adhere to an intention-to-treat analysis, so suggesting high likelihood of bias (-1 of quality).

3 (-1 limitations) ( -1 publication bias). Busse W 2001 and Boushey HA 2005 fail to adhere to an intention-to-treat analysis, so suggesting high likelihood of bias ( -1 of quality). Only two trials were included, from the funnel plot we strongly suspected there was publication bias.

4 (-1 limitations) ( -1 publication bias). Three trials (Boushey HA 2005, Busse W 2001, Huang CJ 2003) have high quality, but all of them fail to adhere to an intention-to-treat analysis, so suggesting high likelihood of bias ( -1 of quality). Three trials were included, from the funnel plot we strongly suspected there was publication bias.

5 ( -1 limitations) ( -1 publication bias).Busse W 2001 and Nathan RA 1998 fail to adhere to an intention-to-treat analysis, so suggesting high likelihood of bias ( -1 of quality). Only two trials were included, from the funnel plot we strongly suspected there was publication bias.

6 ( -1 limitations) ( -1 publication bias) (+1 large effect). Busse W 2001 fails to adhere to an intention-to-treat analysis, so suggesting high likelihood of bias ( -1 of quality). Three trials were included, from the funnel plot we strongly suspected there was publication bias. Large effect (M-H pooled OR $=3.712)$ in the absence of other methodological limitations), so upgrading quality of evidence.

7 ( -1 limitations) ( -1 publication bias).Boushey HA 2005 fails to adhere to an intention-to-treat analysis, so suggesting high likelihood of bias ( -1 of quality). Trials were included, from the funnel plot we strongly suspected there was publication bias.

8 ( -1 limitations) ( -1 publication bias).Boushey HA 2005 and Huang CJ 2003 fail to adhere to an intention-to-treat analysis, so suggesting high likelihood of bias $(-1$ of quality). Trials were included from the funnel plot we strongly suspected there was publication bias.

Preventing recurrent exacerbations is an important goal in asthma therapy. Zafirlukast showed an overall beneficial effect on the symptoms of chronic asthma as measured by asthma exacerbations and other parameters when compared to placebo. Though there is a less-stringent definition for asthma exacerbation (based on patient's current therapy change, oral or inhaled steroids use, worsening symptoms, emergency room treatment or hospitalization, or rescue albuterol use), definitions of a mild or moderate asthma exacerbation are justifiable according to a recently published ATS/ERS statement [20]. On the basis of ATS/ ERS, severe asthma exacerbations can be defined as events that require urgent action on the part of the patient and physician to prevent a serious outcome, such as use of systemic corticosteroids, hospitalization or death from asthma; moderate exacerbations as events that result in a temporary change in treatment, in an effort to prevent the exacerbation from becoming severe; and mild exacerbations that are only just outside the normal range of variation in symptoms or changes in flow rates for the individual patient and may reflect transient loss of asthma control. In our study, the available data demonstrated that zafirlukast only decreased the risk of mild and moderate asthma exacerbations, but not severe asthma exacerbations, such as requiring systemic corticosteroids and emergency visits in chronic persistent asthma. Although zafirlukast was superior to placebo in reducing the risk of asthma exacerbations, our results indicated that patients receiving low-dose ICs from 352 to 400 ug daily had fairly fewer asthma exacerbations than those taking zafirlukast. It was consistent with Ducharme FM's results that, in adults with mild to moderate chronic asthma, the risk of exacerbations requiring systemic glucocorticoids was $60 \%$ higher with daily oral leukotriene receptor antagonists than with doses of ICs equivalent to $400 \mathrm{ug} /$ day inhaled beclometasone [6].

ICs were considered as the first-line treatment for patients with moderate to severe persistent asthma, but some patients require additional treatments or prefer not to use ICs. Our study manifested that the addition of zafirlukast 
to ICs could not reduce the asthma exacerbations as future risk of asthma outcomes. It indicated that zafirlukast, as an add-on therapy, might be possibly associated with improving asthma symptoms but not asthma exacerbations in future. Reid et al. found that zafirlukast significantly improved $\mathrm{FEV}_{1}$ and PEF, and reduced morning waking with asthma and $\beta_{2}$-agonist puffs [22]. In bronchial challenge studies, zafirlukast attenuated the lower airway symptoms and pulmonary response to cat challenge $[23,24]$. Asthma is a complex multifactorial disorder involving a variety of different mechanisms. Environmental exposure and genetic background play a major role in development of asthma and triggering asthma symptoms. Genetic studies have produced heterogeneous results with little replication. More than 100 genes had been reported in connection to asthma or asthma phenotypes since the first study linking a genetic locus to asthma in 1989 [25]. Our recent study systemically explored the network of asthma-related genes where three hundred and twenty-six genes were identified [26]. The poor asthma control is related to deteriorative airway inflammation, asthma-related comorbidities such as obesity, rhinitis, gastroesophageal reflux disease, obstructive sleep apnoea, and exacerbation risk which is an important component to investigate asthma control [27].

In our systematic review, 10 out of twelve trials definitely described subjects characterized by no smoking, but there was not enough information to identify the status of smoking in other two trials $[10,11]$. Active smoking is associated with an increased morbidity from asthma and impairs the response to ICs $[28,29]$. The children exposed to environmental tobacco smoking had impaired recovery after hospitalization for acute asthma [30]. Extensive studies reveal that diet, particularly breast-feeding, is related to the development of asthma. Atopy is an independent risk factor of occupational asthma [31]. Body mass index (BMI) is an important independent predictor of asthma development and poor asthma control and asthma outcome [31], but we did not perform the subgroup analysis because only one trial provided the information on BMI [8]. More available data are needed to reveal the effect of zafirlukast on asthma exacerbations in patients with different BMI. Compared to normal weight asthmatics, the obese children are more likely to have severe disease and airflow obstruction [32].

There are sorts of inflammatory cells and mediators related to asthma mechanisms. An important role in airways inflammation is played by cysteinylleukotrienes, which are powerful agents inducing bronchoconstriction, mucus hypersecretion and airways hyperresponsiveness, and act as chemoattractants for eosinophils in the airways [33]. In patients with mild to moderate persistent asthma, zafirlukast, one of leukotriene receptor antagonists, produced rapid improvement in pulmonary function and daytime asthma symptoms, meanwhile decreasing the need for rescue therapy with $\beta_{2}$-agonist and improving asthma control when combined with ICs [34]. Unexpectedly, we did not find that zafirlukast was superior to placebo in asthma exacerbations and emergency visits in either the first-line and add-on therapies. Furthermore, we did not find difference in asthma exacerbations between zafirlukast and ICs in add-on regimens. However, because of small sample size, it does not seem completely believable that zafirlukast was not superior to placebo in asthma exacerbations requiring systemic corticosteroids, and there was no significant difference in emergency visits for asthma exacerbations between zafirlukast and ICs in the first-line regimen. Additionally, all results from comparisons between zafirlukast, ICs and placebo in the add-on regimens were also somewhat unreliable for a low power. This suggests that more randomized controlled trials or larger sample size are needed to identify these difference among zafirlukast, ICs and placebo.

Our study has some limitations. First, the small number of trials could have lowered the power and lead to relative wide confidence intervals also precluding meta-regression analysis although high quality randomized controlled trials were included. Second, as it is well known, smoking, obesity, allergen, adherence and age are factors modifying the response to antiasthma medications, but this information was not available to be further analyzed.

\section{Conclusions}

This systematic review included 12 randomized controlled trials to assess the efficiency of zafirlukast in preventing asthma exacerbations as future risk in chronic persistent mild to moderate asthma. Our results showed that zafirlukast could decrease risk of mild and moderate but not severe exacerbations as the first-line regimen. Furthermore, it was evidently inferior to ICs in any kinds of exacerbations. Because it has not enough available information to support subgroup and sensitivity analysis, more trials are needed to confirm these conclusions that would benefit the asthma patients in clinical practice.

\section{Abbreviations \\ ATS: American Thoracic Society; Cl: Confidence interval; ERS: European Respiratory Society; $\mathrm{FEV}_{1}$ : Forced expiratory volume in one second; $\mathrm{FEV}_{1} \%$ of predicted: Predicted of forced expiratory volume in one second percentage; GRADE: Grading of Recommendations Assessment, Development, and Evaluation; GINA: Global Initiative for Asthma; ICs: Inhaled corticosteroids; LTRAs: Leukotriene receptor antagonists; OR: Odds ratio; RCTs: Randomized controlled trials.}

\section{Competing interests}

The authors declare that they have no competing interests.

\section{Authors' contributions}

CFC contributed to collect, analyze the data, and write the paper. YL and HPZ participated in the collection of data. GW participated in the design of the study and analysis, and reviewed the manuscript. All authors read and approved the final manuscript. 


\section{Funding}

This study was partly supported by National Natural Science Foundation of China (30971326, 81241002 and 81370122), Sichuan Youth Science and Technology Foundation (No. 2010JQ0008), Youth Science Funding of Sichuan University (2011SCU04B17) and Program for New Century Excellent Talents in University (NCET-12-0380).

Received: 8 February 2014 Accepted: 6 May 2014

Published: 28 May 2014

\section{References}

1. Masoli M, Fabian D, Holt S, Beasley R: The global burden of asthma: executive summary of the GINA Dissemination Committee report. Allergy 2004, 59(5):469-478.

2. Global strategy for asthma management and prevention. 2011, www.ginasthma.org

3. Taylor DR, Bateman ED, Boulet LP, Boushey HA, Busse WW, Casale TB, Chanez P, Enright PL, Gibson PG, De Jongste JC, Kerstjens HA, Lazarus SC, Levy ML, O'Byrne PM, Partridge MR, Pavord ID, Sears MR, Sterk PJ, Stoloff SW, Szefler SJ, Sullivan SD, Thomas MD, Wenzel SE, Reddel HK: A new perspective on concepts of asthma severity and control. Eur Respir J 2008 32(3):545-554.

4. Thompson PJ, Salvi S, Lin J, Cho YJ, Eng P, Abdul Manap R, Boonsawat W, Hsu JY, Faruqi RA, Moreno-Cantu JJ, Fish JE, Ho JC: Insights, attitudes and perceptions about asthma and its treatment: Findings from a multinational survey of patients from 8 Asia-Pacific countries and Hong Kong. Respirology 2013, 18(6):957-967.

5. Jorgensen IM, Jensen VB, Bulow S, Dahm TL, Prahl P, Juel K: Asthma mortality in the Danish child population: risk factors and causes of asthma death. Pediatr Pulmonol 2003, 36(2):142-147.

6. Ducharme FM: Inhaled glucocorticoids versus leukotriene receptor antagonists as single agent asthma treatment: systematic review of current evidence. BMJ 2003, 326(7390):621.

7. The Cochrane collaboration: Cochrane handbok for systematic reviews of interventions version 5.0.0.2008. http://www.cochrane-handbook.org.

8. Boushey HA, Sorkness CA, King TS, Sullivan SD, Fahy JV, Lazarus SC, Chinchilli VM, Craig TJ, Dimango EA, Deykin A, Fagan JK, Fish JE, Ford JG, Kraft M, Lemanske RFJ, Leone FT, Martin RJ, Mauger EA, Pesola GR, Peters SP, Rollings NJ, Szefler SJ, Wechsler ME, Israel E: Daily versus as-needed corticosteroids for mild persistent asthma. N Engl J Med 2005, 352(15):1519-1528.

9. Huang CJ, Wang CH, Liu WT, Yang MC, Lin HC, Yu CT, Shiao CJ, Tan CC, Yang CK, Kuo HP: Zafirlukast improves pulmonary function in patients with moderate persistent asthma receiving regular inhaled steroids: a prospective randomized control study. Chang Gung Med J 2003, 26(8):554-560

10. Brabson JH, Clifford D, Kerwin E, Raphael G, Pepsin PJ, Edwards LD, Srebro S, Rickard K: Efficacy and safety of low-dose fluticasone propionate compared with zafirlukast in patients with persistent asthma. Am J Med 2002, 113(1):15-21.

11. Nathan RA, Bleecker ER, Kalberg C: A comparison of short-term treatment with inhaled fluticasone propionate and zafirlukast for patients with persistent asthma. Am J Med 2001, 111(3):195-202.

12. Busse W, Wolfe J, Storms W, Srebro S, Edwards L, Johnson M, Bowers BW, Rogenes PR, Rickard K: Fluticasone propionate compared with zafirlukast in controlling persistent asthma: a randomized double-blind, placebocontrolled trial. J Fam Pract 2001, 50(7):595-602.

13. Kim KT, Ginchansky EJ, Friedman BF, Srebro S, Pepsin PJ, Edwards L, Stanford RH, Rickard K: Fluticasone propionate versus zafirlukast: effect in patients previously receiving inhaled corticosteroid therapy. Ann Allergy Asthma Immunol 2000, 85(5):398-406.

14. Virchow JC Jr, Prasse A, Naya I, Summerton L, Harris A: Zafirlukast improves asthma control in patients receiving high-dose inhaled corticosteroids. Am J Respir Crit Care Med 2000, 162(2 Pt 1):578-585.

15. Bleecker ER, Welch MJ, Weinstein SF, Kalberg C, Johnson M, Edwards L, Rickard KA: Low-dose inhaled fluticasone propionate versus oral zafirlukast in the treatment of persistent asthma. J Allergy Clin/mmunol 2000, 105(6 Pt 1):1123-1129.

16. Busse W, Nelson H, Wolfe J, Kalberg C, Yancey SW, Rickard KA: Comparison of inhaled salmeterol and oral zafirlukast in patients with asthma. J Allergy Clin Immunol 1999, 103(6):1075-1080.
17. Nathan RA, Bernstein JA, Bielory L, Bonuccelli CM, Calhoun WJ, Galant SP, Hanby LA, Kemp JP, Kylstra JW, Nayak AS, O'Connor JP, Schwartz HJ, Southern DL, Spector SL, Williams PV: Zafirlukast improves asthma symptoms and quality of life in patients with moderate reversible airflow obstruction. J Allergy Clin Immunol 1998, 102(6 Pt 1):935-942.

18. Fish JE, Kemp JP, Lockey RF, Glass M, Hanby LA, Bonuccelli CM: Zafirlukast for symptomatic mild-to-moderate asthma: a 13-week multicenter study. The ZafirlukastTrialists Group. Clin Ther 1997, 19(4):675-690.

19. Spector SL, Smith LJ, Glass M: Effects of 6 weeks of therapy with oral doses of ICl 204,219, a leukotriene D4 receptor antagonist, in subjects with bronchial asthma. ACCOLATE Asthma Trialists Group. Am J RespirCrit Care Med 1994, 150(3):618-623.

20. Reddel HK, Taylor DR, Bateman ED, Boulet LP, Boushey HA, Busse WW, Casale TB, Chanez P, Enright PL, Gibson PG, De Jongste JC, Kerstjens HA, Lazarus SC, Levy ML, O'Byrne PM, Partridge MR, Pavord ID, Sears MR, Sterk PJ, Stoloff SW, Sullivan SD, Szefler SJ, Thomas MD, Wenzel SE: An official American Thoracic Society/European Respiratory Society statement: asthma control and exacerbations: standardizing endpoints for clinical asthma trials and clinical practice. Am J Respir Crit Care Med 2009, 180(1):59-99.

21. Jia CE, Zhang HP, LV Y, Liang R, Jiang YQ, Powell H, Fu JJ, Wang L, Gibson PG, Wang G: The Asthma Control Test and Asthma Control Questionnaire for assessing asthma control: Systematic review and meta-analysis. J Allergy Clin Immunol 2013, 131(3):695-703.

22. Reid DW, Misso NL, Aggarwal S, Thompson PJ, Johns DP, Walters EH: Tolerance and rebound with zafirlukast in patients with persistent asthma. J Negat Results Biomed 2008, 7:3.

23. Corren J, Spector S, Fuller L, Minkwitz M, Mezzanotte W: Effects of zafirlukast upon clinical, physiologic, and inflammatory responses to natural cat allergen exposure. Ann Allergy Asthma Immunol 2001, 87(3):211-217

24. Phipatanakul W, Eggleston PA, Conover-Walker MK, Kesavanathan J, Sweitzer D, Wood RA: A randomized, double-blind, placebo-controlled trial of the effect of zafirlukast on upper and lower respiratory responses to cat challenge. J Allergy Clin Immunol 2000, 105(4):704-710.

25. March ME, Sleiman PM, Hakonarson H: Genetic polymorphisms and associated susceptibility to asthma. Int J Gen Med 2013, 6:253-265.

26. Liang $R$, Wang $L$, Wang $G$ : New insight into genes in association with asthma: literature-based mining and network centrality analysis. Chin Med J (Engl) 2013, 126(13):2472-2479.

27. Fu JJ, McDonald VM, Wang G, Gibson P: Asthma control: How it can be best assessed? Curr Opin Pulm Med 2014, 20(1):1-7.

28. Lemiere C, Boulet LP: Cigarette smoking and asthma: a dangerous mix. Can Respir J 2005, 12(2):79-80.

29. Chalmers GW, Macleod KJ, Little SA, Thomson LJ, McSharry CP, Thomson NC: Influence of cigarette smoking on inhaled corticosteroid treatment in mild asthma. Thorax 2002, 57(3):226-230.

30. Abulhosn RS, Cai WJ: Passive smoke exposure impairs recovery after hospitalization for acute asthma. Arch Pediatr Adolesc Med 1997, 151(2):135-139.

31. Remen T, Acouetey DS, Paris C, Zmirou-Navier D: Diet, occupational exposure and early asthma incidence among bakers, pastry makers and hairdressers. BMC Public Health 2012, 12:387.

32. Lang JE, Hossain J, Smith K, Lima JJ: Asthma severity, exacerbation risk and controller treatment burden in underweight and obese children. J Asthma 2012, 49(5):456-463.

33. Busse W, Kraft M: Cysteinylleukotrienes in allergic inflammation: strategic target for therapy. Chest 2005, 127(4):1312-1326.

34. Stoloff SW: The role of LTRAs in the management of persistent asthma. Postgrad Med 2000, 108(4 Suppl):22-31.

\section{doi:10.1186/2049-6958-9-30}

Cite this article as: Chen et al: Does zafirlukast reduce future risk of asthma exacerbations in adults? Systematic review and meta-analysis. Multidisciplinary Respiratory Medicine 2014 9:30. 